\title{
VELOCITY-SPACE STABILITY OF COUNTERSTREAMING-ION TOKAMAK PLASMAS
}

BY

D. L, JASSBY, R. M, KULSRUD, AND $F$, $W$, PERKINS

\section{PLASMA PHYSICS LABORATORY}

\section{MASTER}

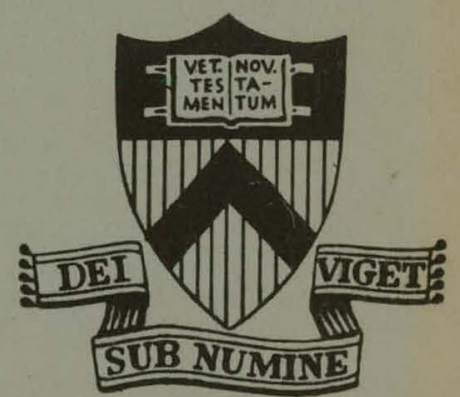

TICTOIRITION OF THIS DOCUMENT IS UNLIMITED

\section{PRINCETON \\ UN IVERSITY PRINCETON, NEW JERSEY}

This work was supported by U. S. Energy Research and Development Administration Contract E(11-1)-3073. Reproduction, translation, publication, use and disposal, in whole or in part, by or for the United States Government is permitted. 


\section{DISCLAIMER}

This report was prepared as an account of work sponsored by an agency of the United States Government. Neither the United States Government nor any agency Thereof, nor any of their employees, makes any warranty, express or implied, or assumes any legal liability or responsibility for the accuracy, completeness, or usefulness of any information, apparatus, product, or process disclosed, or represents that its use would not infringe privately owned rights. Reference herein to any specific commercial product, process, or service by trade name, trademark, manufacturer, or otherwise does not necessarily constitute or imply its endorsement, recommendation, or favoring by the United States Government or any agency thereof. The views and opinions of authors expressed herein do not necessarily state or reflect those of the United States Government or any agency thereof. 


\section{DISCLAIMER}

Portions of this document may be illegible in electronic image products. Images are produced from the best available original document. 
This report was prepared as an account of work sponsored by the United States Government. Neither the United States nor the United States Energy Research and Development Administration, nor any of their employees, nor any of their contractors, subcontractors, or their employees, makes any warranty, express or implied, or assumes any legal liability or responsibility for the accuracy, completeness or usefulness of any information, apparatus, product or process disclosed, or represents that its use would not infringe privately owned rights.

Printed in the United States of America.

Available from

National Technical Information Service

U. S. Department of Commerce 5285 Port Royal Road

Springfield, Virginia 22151

Price: Printed Copy $\${ }^{*} ;$ Microfiche $\$ 1.45$

* pages

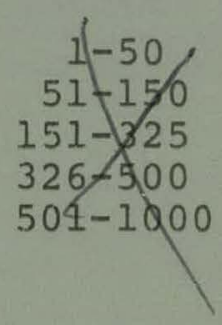

NTIS

Selling Price

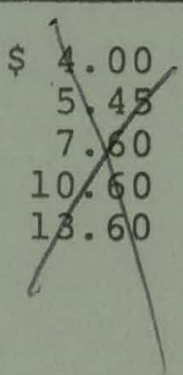




\author{
VELOCITY-SPACE STABILITY OF COUNTERSTREAMING-ION \\ TOKAMAK PLASMAS \\ D. L. JASSBY, R. M. KULSRUD, F. W. PERKINS \\ Princeton University, Plasma Physics Laboratory \\ Princeton, New Jersey 08540
}

\begin{abstract}
The steady-state CBT/CIT ion velocity distributions are stable to all electrostatic and electromagnetic infinite-medium modes. This stability is due to the large thermal spread of the distributions $\left(\mathrm{T}_{\text {hot }} \geq 1.5 \mathrm{~T}_{\mathrm{e}} \cdot \mathrm{v}_{\mathrm{ti}} / \mathrm{u}>1 / 3\right)$, and to the fact that tokamak equilibrium allows the mean streaming velocity, $u$, to be only a small fraction of the Alfven velocity.
\end{abstract}

M $\triangle T T-1233$

April 1976

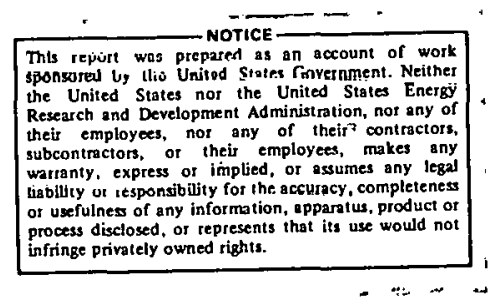


VELOCITY-SPACE STABILITY OF COUNTERSTREAMING-ION TOKAMAK PLASMAS

In counterstreaming-ion tokamak plasmas, the ion population makes up two distinct, quasi-thermal velocity distributions, oppositely displaced in velocity along the magnetic axis, as shown in Fig. 1. These distributions are maintained by introducing all plasma ions by means of energetic neutral-atom beams, injected parallel and antiparallel to the magnetic axis, and by minimizing recycling of decelerated ions that leave the hot plasma region. Counterstreaming distributions of deuterons and tritons form the basis of the CBT fusion reactor concept ${ }^{1-3}$ (also referred to as the CIT, for counterstreaming-ion torus). The optimal performance of this fusion reactor depends, inter alia, on the absence of microinstabilities that would enhance the slowing-down rate of the energetic ions. ${ }^{1-4}$ In this note we summarize stability treatments that show that for all practical conditions, the steady-state CBT/CIT velocity distributions are stable to electrostatic and electromagnetic modes. This stability is due, first of all, to the large thermal spread of the distributions, and second, to the fact that tokamak equilibrium allows the streaming velocity to be only a small fraction of the Alfven velocity.

Fokker-Planck calculations ${ }^{1}$ have shown that the ion velocity distributions $f_{i}(v)$ can be approximated by shifted Maxwellians (see Fig. 1):

$$
f_{i}(v)=\frac{M_{i}^{3 / 2} n_{b}}{(2 \pi)^{3 / 2} T_{\perp} T_{\|}^{1 / 2}} \exp \left[-M_{i}\left(v_{\|} \pm u_{b}\right)^{2} / 2 T_{\|}-M_{i} v_{\perp}^{2} / 2 T_{\perp}\right]
$$


Here, $v_{\|}$and $v_{1}$ are velocities parallel and perpendicular to the magnetic axis, while $T_{\|}$and $T_{\perp}$ are the parallel and perpendicular temperatures of the ion distributions. In the following, the electrons are taken as Maxwellian, and the plasma is assumed to be homogeneous. For simplicity, we assume that the counterstreaming distributions have the same amplitude, temperature, and displaced velocity, and that all ions are identical.

We define $\Delta W=2 u_{b} v_{t i} M_{i}$, where $v_{t i}=\left(2 T_{\|} / M_{i}\right)^{1 / 2}$. Then $\Delta \mathrm{W} / \mathrm{w}_{\mathrm{b}}=4\left(\mathrm{~T}_{\|} / \mathrm{w}_{\mathrm{b}}\right)^{1 / 2}$, where $\mathrm{w}_{\mathrm{b}}=1 / 2 \mathrm{M}_{\mathrm{i}} \mathrm{u}_{\mathrm{b}}{ }^{2}$. The Fokker-Planck calculations för steady-state operation reveal the following relations: ${ }^{\mathrm{I}} \mathrm{H}_{\mathrm{I}} \geqslant 1.5 \mathrm{~T}_{\mathrm{e}}, \mathrm{T}_{\mathcal{L}}>\mathrm{T}_{\|}, \mathrm{v}_{\mathrm{ti}} / \mathrm{u}_{\mathrm{b}}>1 / 3, \Delta \mathrm{W} / \mathrm{W}_{\mathrm{b}}>4 / 3$.

The sources of free energy for velocity-space instability are $\partial f_{i} / \partial v_{\|}^{2}>0$, for $\left|v_{\|}\right|<u_{b}$, and the anisotropic ion pressure $\left(p_{\|}>p_{1}\right)$. First we consider electrostatic modes, with $\omega$ not near $\omega_{\mathrm{Ci}}$, the ion cyclotron frequency. The stability boundaries for such modes in counterstreaming systems have been discussed by stringer ${ }^{5}$ and by Forslund and Shonk. 6 They show that ion-ion modes (including the "two-stream" instability) are stable if $\mathrm{T}_{\|} \geq 1 / 2 \mathrm{~T}_{\mathrm{e}}$. When $\mathrm{T}_{\|}>\mathrm{T}_{\mathrm{e}}$ (as in the present: situation), electron-ion modes are stable if $u_{b} \lesssim 10\left(T_{c} / M_{i}\right) 1 / 2$; for injection energy, $\check{~} 100 \mathrm{keV}$, this condition is satisfied if $T_{e} \geq 0.7 \mathrm{keV}$. These criteria hol.d for waves propagating.: at arbitrary angles.

The stability of electromagnetic modes with $\omega$ not near $\omega_{c i}$ depends in part on the accessible range of $u_{b}$. In calculating the poloidal beta of a CBT plasma, the streaming energy density can be treated formally as if it were a thermal pressure (A. $H$. Boozer, unpublished). That is, even when the thermal energy of the plasma is negligible, for equilibrium we require that 


$$
\frac{8 \pi M_{i} n_{i} u_{b}^{2}}{B_{p}^{2}} \approx \frac{1}{\varepsilon}
$$

so that

$$
\frac{u_{b}}{v_{A l f}} \approx \frac{1}{q}\left(\frac{\varepsilon}{2}\right)^{1 / 2}
$$

where $v_{A l f}$ is the Alfven velocity, $\varepsilon$ is the inverse aspect ratio, and $q=\varepsilon_{B_{t}} / B_{p}$ is the safety factor at the limiter. For practical conditions, $q>2$ and $\varepsilon \leqslant 1 / 3$, so that $u_{b} / v_{A l f} ₹ 0.2$.

Gaffey ${ }^{7}$ shows that a minimum condition for the excitation of ordinary electromagnetic waves propagating perpendicular to $\vec{B}$ is that $\left(u_{b} / v_{A l f}\right)^{2}, \geq 1 / 2$. Montgomery et al. ${ }^{8}$ obtain numerically a similar requirement for exciting magnetosonic and Alfven modes;;" propagating at arbitrary angles to the magnetic field. This instability threshold cannot be reached by the CBT velocity distributions.

Electrostatic ion cyclotron waves $\left(k_{\perp}>k_{11}\right)$ have been treated by Weibel ${ }^{9}$ and by Perkins. ${ }^{10}$ For $\mathrm{T}_{\|}>\mathrm{T}_{\mathrm{e}}$, their treatmenta give essentially the same criterion, namely that these modes are stable when $\Delta \mathrm{W} / \mathrm{W}_{\mathrm{b}} \geq 0.8 \mathrm{~T}_{\mathrm{e}} / \mathrm{T}_{\mathcal{l}}$; this condition is always satisfied by the steady-state CBT distributions. A recent experiment in a linear device ${ }^{11}$ has demonstrated the validity of this stability criterion.

Finally, the excitation of elcctromagnetic ion cyclotron waves by counterstreaming ions has been investigated by Perkins. 10 While interaction between the counterstreaming distributions tends to make the waves grow, an important stabilizing mechanism is cyclotron damping by each distribution itself. 
Excitation of these modes requires that $u_{b} \geq 1 / 3 v_{A l f}, \cdot$ and in any event there i.s stability when $\Delta W / W_{b} \geq 1$.

Table 1 summarizes the stability criteria, and indicates the range of parameters of "ideal" CBT/CIT distributions, 1,2 which are bound to be the least stable. That is, a substantial population of colder ions enhances the slowing-down rate of energetjc ions, resulting in a smaller $u_{b}$ and increased. $\Delta W$ and $\mathrm{T}_{\|}$- (Of: course, the cold-ion population also degrades reactor performance.) Although we have assumed in nur eurvey that the counterstreaming distributions are identical, we expect essentially the same results if this condition is relaxed...

(The above, analysis applies only to steady-state conditions. At the start of injection, the ion distributions are more peaked, with a smaller $\Delta W$ and a larger $u_{b}$, so that instabilities can be excited. This transient phase, however, lasts onjy one or two slowing-down periods, typically less than $0.5 \mathrm{s.}$

Turning briefly to MHD modes that could result from the anisotropj.c pressure, it is clear that the "fixehuse" instability" cannot arise in tokamak operation, where $\mathrm{p}_{11} / \mathrm{B}^{2} \ll 1$. Connor and Hastie ${ }^{12}$ have shown that parallel beam injection leading to $p_{\|}>p_{1}$ actually has a stabilizing influence on the localized. interchange modes, provided that $\mathrm{dp}_{\| 1} / \mathrm{dr}<0$.

Concerning the other two potential problems that have been mentioned by cordey ${ }^{4}$ in his discussion of the CBT concept, we note that tokamak operation with comparable ion and electron energy densities has already been achieved in recent beaminjection experiments on the ATC, ORMAK, and TFR devices 
[unpublished results]. It seems likely that with further increases in injection power, large ratios of ion energy to electron energy can be obtained. Then the fundamental plasma physics problem facing implementation of CBT/CIT operation is the need to minimize the population of nonstreaming ions. Further theoretical investigations are required also concerning stability against finite-medium modes, such as universal instabilities and the trapped-electron mode.

\section{ACKNOWLEDGMENT}

This work was supported by U.S. Energy Research and Development Administration Contract $\mathrm{E}(11-1)-3073$. 
$\begin{array}{ccc}. \quad \text { k } & -6- \\ 4: & \text { REFERFNCES }\end{array}$

1. Kulsyud, R. M., and Jassby, D. L., Nature 259, \$541-544 (1976).

2. Jassby, D. L., Nucl. Fusion 16, 15-30 (1976).

3. Cordey, J. G., and Core, W. G. F., Nucl. Fusion 15, 710-713 (1975).

4. Cordey, J. G., Nature 259, 526 (1976).

5. Stringer, T. E., J. Nuclear Energy, Part C 6, 267-287 (1964).

6. Forslund, D. W., and Shonk, C. R., Phys. Rev. Lett. 25, 281$2.84(9.970)$.

7. Gaffey, J. D., J. Plasma Physics 13, Part 3, 563-569 (1975).

8. Montgomery, M. D., et al., Phys. Rev. Lett. 35, 667-670 $(1.975)$

9. Weibel, E. S., Phys. Fluids 13, 3003-3006 (1970).

10. Perkins, F. W., Princeton Plasma Physics Lab. Report MATT1141 (1975), submitted to Physics of Fluids.

11. H. W. Hendel, et al., Phys. Rev. Lctt. 36, 319-322 (1976).

12. Connor: J. W., and Hastie, R. J., Proc. Seventh Europ. Conf. on Controlled Fusion and Plasma Physics (Lausanne, 1975) I, 102. 
Table 1 . Stability Criteria for Counterstreaming-Ion
Velocity Distributions

)

$v$

Sufficient Condition for stability

Practical CBT Parameters

\begin{tabular}{|c|c|c|}
\hline Mode & $\begin{array}{c}\text { Sufficient Condition } \\
\text { for stability }\end{array}$ & $\begin{array}{c}\text { Practical } \\
\text { CBT Parameters }\end{array}$ \\
\hline $\begin{array}{l}\text { Electrostatic, } \\
\omega \text { not near } \omega_{c i}\end{array}$ & $\begin{array}{c}\mathrm{T}_{\|}>1 / 2 \mathrm{~T}_{\mathrm{e}}{ }^{\prime} 1 / 2 \\
\mathrm{u}_{\mathrm{b}} \lesssim 10\left(\mathrm{~T}_{\mathrm{e}} / \mathrm{M}_{\mathrm{i}}\right) 1 / 2\end{array}$ & $\begin{array}{c}\mathrm{T}_{\|} \geqslant 1.5 \mathrm{~T}_{\mathrm{e}} \\
\mathrm{u}_{\mathrm{b}}<5\left(\mathrm{~T}_{\mathrm{e}} / \mathrm{M}_{\mathrm{i}}\right) \stackrel{\mathrm{I} / 2}{ }\end{array}$ \\
\hline $\begin{array}{c}\text { Electromagnetic, } \\
\omega \text { not near } \omega_{c i}\end{array}$ & $u_{b}<1 / 2 v_{A l f}$ & $\mathrm{u}_{\mathrm{b}} \lessdot 1 / 5 \mathrm{v}_{\mathrm{Al}} \mathrm{f}$ \\
\hline $\begin{array}{l}\text { Electrostatic ion } \\
\text { cyclotron waves }\end{array}$ & $\Delta \mathrm{W} / \mathrm{W}_{\mathrm{b}}>0.8 \mathrm{~T}_{\mathrm{e}} / \mathrm{T}_{\perp}$ & $\Delta \mathrm{W} / \mathrm{W}_{\mathrm{b}}>2 \mathrm{~T}_{\mathrm{e}} / \mathrm{T}_{\perp}$ \\
\hline $\begin{array}{l}\text { Electromagnetic ion } \\
\text { cyclotron waves }\end{array}$ & $\begin{array}{l}\mathrm{u}_{\mathrm{b}}<1 / 3 \mathrm{v}_{\mathrm{Alf}} \\
\text { or } \Delta \mathrm{W} / \mathrm{w}_{\mathrm{b}} \geq 1\end{array}$ & $\Delta \mathrm{W} / \mathrm{w}_{\mathrm{b}}>4 / 3$ \\
\hline
\end{tabular}




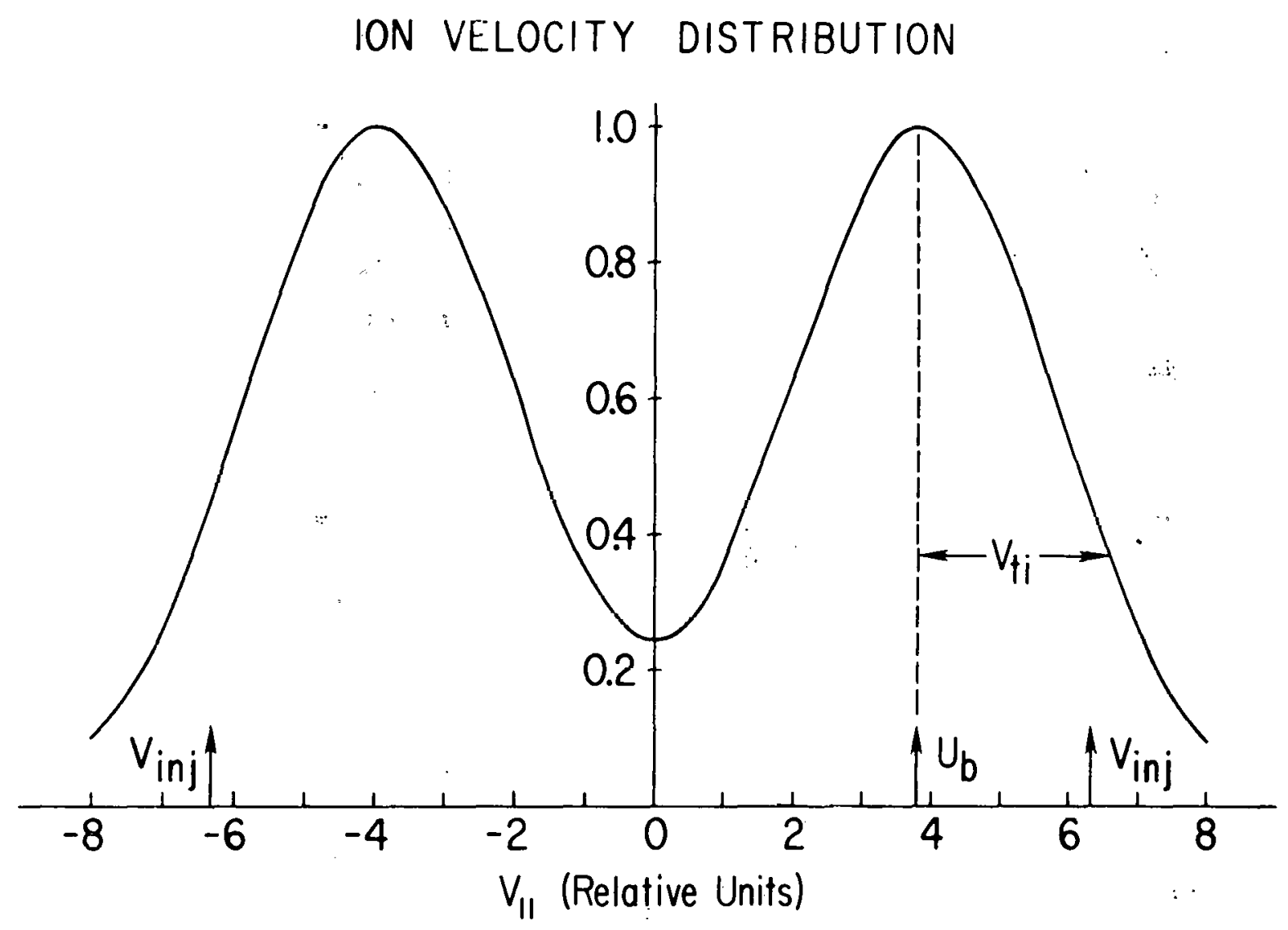

763236

Fig. 1. Counterstreaming-ion velocity distributions parallel to the toroidal magnetic field. Ions are injected at $v_{\|}=v_{i n j}$, and removed at $v_{\|}<2$. $u_{b}$ is the mean streaming ve-. locity, and $v_{t i}$ is the ion "parallelb "thermal" velocity. 